\title{
RECONSIDERANDO LAS MIGRACIONES INTERNACIONALES: HACIA UNA POLÍTICA MIGRATORIA DE FRONTERAS ABIERTAS
}

\author{
RECONSIDERING INTERNATIONAL MIGRATIONS: \\ TOWARDS AN OPEN BORDERS MIGRATORY POLICY
}

Nerea González García

Juan Carlos Velasco, El azar de las fronteras. Politicas migratorias, ciudadanía y justicia, México: Fondo de Cultura Económica, 2016.

El gran protagonismo que las migraciones internacionales ocupan en nuestra era, la cual podría ser descrita como "la era de la movilidad", resulta innegable. En este sentido, el libro de Velasco se encuentra de plena actualidad y se torna fundamental para entender, desde distintas perspectivas, los procesos migratorios que perfilan nuestro presente. A través de un análisis de las fronteras, comprendidas éstas en todas sus dimensiones políticas, jurídicas, morales, antropológicas y simbólicas (p. 11), Velasco analiza los retos propuestos por las migraciones internacionales a los que los gobiernos estatales se enfrentan. La democracia liberal, sus principios y valores, parecen estar en juego una vez que la cuestión de la movilidad humana es comprendida como un derecho desde la óptica de la justicia. Del mismo modo, la noción tradicional de ciudadanía nacional es puesta en entredicho y necesitaría, por tanto, ser revisada caminando así hacia lo que Velasco conceptualiza como "ciudadanía universal" (concretamente en el segundo capítulo, aunque también en el quinto). Es preciso subrayar que el autor no aboga por una supresión de las fronteras - tema que es discutido brevemente al término de la última parte del libro (pp. 316-319) o, de manera fugaz, en el epílogo (p. 331) — sino que la propuesta de Velasco es la de una política migratoria de fronteras abiertas (cap. 6) que reconozca la libertad de circulación como un derecho básico a todo ser humano.

La primera parte del libro ofrece una introducción a los temas que, en las cinco partes restantes, pasarán a ser tratados con exhaustividad. Los temas principales en torno a los que gira el análisis son, a grandes rasgos; la categoría de ciudadanía, la migración comprendida desde un enfoque transnacional, límites 
o fronteras de la democracia liberal, movilidad humana como derecho en clave de justicia global, pluralismo cultural, políticas migratorias, y la erosión de las capacidades gestoras y decisorias de los gobiernos estatales tradicionales en lo que respecta a los procesos migratorios.

Además de una exposición clara, concisa y bien argumentada de sus ideas, uno de los aspectos más positivos a destacar de El azar de las Fronteras es el de la elaboración de propuestas constructivas. Así, el ensayo mantiene un ritmo muy vivo en el cual se intercalan tanto críticas como salidas y alternativas a los problemas expuestos. Entre tales propuestas positivas, se sitúan la llamada hacia una ciudadanía universal mediatizada por los derechos humanos, la creación de instituciones de gobernanza global y el esbozo de una política migratoria de fronteras abiertas, entre otras. De este modo, el ensayo constituye un análisis completo que trasciende el ámbito meramente negativo o crítico. Al mismo tiempo, se trata de un libro que, a pesar de poseer un carácter teórico, mantiene siempre un estrecho contacto con la realidad y los procesos actuales de nuestro tiempo. Sin seguir estrictamente el orden prescrito por el ensayo, este artículo busca resaltar los aspectos fundamentales de la argumentación desarrollada por Velasco, ofreciendo así un recorrido general a través del contenido del libro.

Comenzando por hacer referencia al título del ensayo, es cierto que el azar toma parte en el hecho de haber nacido a un lado de la frontera, es decir, en un país y no en otro y, por tanto, en la adquisición de una determinada nacionalidad que puede tanto abrir puertas como cerrarlas. Sin embargo, una debe ser cuidadosa con la utilización del término "azar". Como apunta Velasco, "el azar es un nombre más de los muchos empleados a lo largo de la tradición occidental para referirse al territorio de lo irracional y, por extensión, de todo aquello que escapa del control humano [...] usados habitualmente como cobertura ideológica para justificar graves decisiones" (p. 20). Dicho de otro modo, reducir el origen de los privilegios que una obtiene al nacer en un determinado territorio al azar, no hace sino ocultar el origen estructural de las desigualdades en las que éstos se apoyan. Tales desigualdades, no debe olvidarse, son resultado de una influencia y actuación humana y constituyen al mismo tiempo la expresión de una determinada voluntad de poder. Por tal motivo, como Velasco se empeña en resaltar, éstas no "escapan al control humano" sino más bien todo lo contrario.

Del mismo modo, las fronteras ni son fruto del mero azar ni tampoco surgen, en su mayoría, naturalmente de diferencias en el terreno - aunque puedan apoyarse en éstas- Recurrir a estos términos conduciría en última instancia a señalar la inamovilidad de las fronteras y a aducir su existencia y trazado como hechos inal- 
terables. Contrariamente, Velasco busca romper con tal naturalización de las fronteras, presente tanto en la ciencia como en la filosofía política, proponiendo una comprensión de la frontera como institución, como creación y artificio humano y como un constructo histórico-político. Las fronteras no surgen espontáneamente, sino que son erigidas por distintos actores políticos, en este caso los Estados, como instrumentos a través de los cuales administrar y "ordenar el mundo desde la óptica del poder” (p. 10). Así, lejos de un carácter fortuito, poseen un objetivo de demarcación específico: "las fronteras estatales marcan los límites entre entidades territoriales políticamente independientes y, por lo tanto, entre ámbitos jurisdiccionales diferenciados" (p. 81). Dicho de otro modo, y, siguiendo de nuevo a Velasco, "con ellas se señala a qué derecho está sometida una población, se determina a qué personas e instituciones ejercen autoridad sobre un determinado territorio y se define finalmente el cuerpo de ciudadanos que integran la comunidad política" (p.83).

En efecto, las fronteras actúan como mecanismos de demarcación y de dotación de derechos. Por ello, las fronteras son un asunto nada banal; en el orden jurídico éstas resultan decisorias en el curso y desarrollo de una vida. Del mismo modo, la posesión de una determinada nacionalidad se encuentra ligada al acto de nacimiento en un territorio específico. Así, teoriza Velasco, la nacionalidad se perfila como una especie de "propiedad privada" (p. 17), de la cual una pasa a ser poseedora por el azaroso hecho de nacer en un determinado país. Además, la nacionalidad dota de derechos, obligaciones, bienes y servicios a quien la obtiene, es decir, le otorga a una el estatus de ciudadana. Es precisamente esta vinculación entre nacionalidad y ciudadanía la que Velasco se propone romper. Cuestión nada banal, ya que el reconocimiento de la existencia social y política de una persona dentro de una determinada comunidad política depende de la categoría de ciudadanía, a través de la cual se adquieren tanto derechos como obligaciones con la comunidad en la que se participa. De este modo - y calificando la ciudadanía como "producto político artificial" (p. 75)_ Velasco adopta un enfoque transnacional a la hora de observar las migraciones ya que éste posee una "capacidad heurística de arrojar luz sobre las contradicciones internas del proyecto moderno de ciudadanía nacional" (p. 100). Así, son los mismos procesos migratorios los que la erosionan y cuestionan; "se hace especialmente visible el desacoplamiento o desajuste entre territorio y ciudadania que generan las migraciones internacionales” (p. 163).

Ciertamente, tales procesos migratorios ponen en cuestión muchas de las nociones y categorías tradicionales, conectadas con la demarcación del territorio, en las que las democracias liberales se basan. $\mathrm{O}$, dicho de otro modo, presentan retos y desafíos a superar — precisamente la capacidad de los gobiernos estatales para 
hacerles frente es una de las cosas que Velasco estudia en su ensayo- - Al mismo tiempo, el autor propone entender la migración desde una perspectiva holista, es decir, en conexión con otros muchos procesos que la rodean y no como un fenómeno aislado. Así, podría, razonablemente, hablarse de un aumento de la migración, pero tal afirmación debería entonces ser contextualizada correctamente dentro de un amasijo de procesos económicos y sociales globalizantes que, entre muchas otras cosas, han modificado las condiciones en las que movilidad humana tiene lugar. Por ello, Velasco propone comprender los procesos migratorios contemporáneos desde el contexto de la globalización ya que ésta "ha modificado las condiciones cognitivas y materiales en las que los individuos emprenden la aventura migratoria" (p. 33).

En el plano estatal, los procesos globalizantes ponen en cuestión las capacidades y funciones tradicionales del Estado ya que, como indica Velasco, "la nueva espacialidad de un mundo enormemente ensanchado, a la vez que comprimido, por los procesos de globalización ha suscitado un amplio debate sobre la decreciente autosuficiencia de los Estados, ideal igualmente asociado a la noción de soberanía" (p. 102). Este debate se sitúa en una escena de derecho internacional que erosiona y relativiza la noción de soberanía estatal — sometida a crítica por Velasco a lo largo de todo su ensayo- - en la cual los gobiernos estatales se apoyan para reclamar su propia preponderancia, autonomía y autosuficiencia. Los gobiernos estatales encontrarían en la idea de territorio el último reducto en el que apoyarse para seguir defendiendo el rasgo westfaliano de soberanía estatal (p. 104) en medio de los conflictos existentes entre intereses nacionales y globalización.

Esto es lo que lleva a Velasco a denunciar cómo, frente a esta pérdida de poder estatal o crisis, el Estado nacional "requiere de continuos actos de reafirmación ante sus propios ciudadanos" (p. 105). Así, se insiste en el derecho soberano al control de las fronteras del propio territorio y se endurecen las políticas migratorias. La pérdida de poder debe "compensarse" por otro lado, subrayando el poder en el propio territorio, compensación que se realiza a expensas de las vidas de muchas personas que, debido a las ineficaces políticas migratorias y al cierre de fronteras, viven su vida precariamente o incluso pierden la vida en el intento. Para ilustrar este punto, basta con traer a nuestra mente por un instante al presidente de los Estados Unidos. Donald Trump ofrece a la perfección el ejemplo de tal necesidad de actos de reafirmación al subrayar incansablemente, incluso antes de llegar al poder, la necesidad de la construcción de un gran muro fronterizo con México que blinde el paso de inmigrantes.

Precisamente, Velasco ofrece un pasaje de lo más revelador respecto a los muros y su componente propagandístico: "en el fondo, su relevancia estriba no 
tanto en su dudosa eficiencia como en su ostentosa visibilidad, esto es, en los efectos performativos que se les adjudican. Los muros fronterizos no se levantan como instrumentos efectivos de defensa ante un enemigo exterior. Lo que prevalece es su valor icónico" (p.85). Este efecto performativo, sin embargo, es un efecto que se realiza a costa de la vida real de muchas personas que tratan de cruzar tales muros fronterizos. La insistencia en la construcción, mantenimiento y reforzamiento de éstos se realiza casi siempre en nombre de la defensa y seguridad nacional.

Así, desde la primera parte introductoria Velasco ya señala el énfasis de los gobiernos estatales en un discurso securitario que, sin embargo "adolece del grave defecto de focalizar la atención en los procesos migratorios como si se tratara de un fenómeno aislado y ajeno al resto de dinámicas sociales" (p. 43). Las migraciones son caracterizadas como amenazas para la seguridad y estabilidad nacional y, por tanto, como algo a detener a toda costa. Como indica Velasco, "la preocupación por la justicia social se ve así desplazada por el afán de seguridad, una tendencia que conduce a la configuración de un modelo de sociedad excluyente y controladora" (p. 41). Aplicando este análisis a nuestra realidad, es indudable que, a lo largo de todo el continente europeo, asistimos efectivamente a una intensificación de los controles fronterizos y a una insistencia en la amenaza que las migraciones suponen para la coherencia social de un país. Respecto a esto último, no hay sino que observar el triunfo de partidos de ultra-derecha en las últimas elecciones europeas cuyo discurso se basa precisamente en la fabricación de amenazas que la migración supondría para el país y a las que éste debe hacer frente con duras medidas de seguridad, lo que se traduce como políticas anti-migratorias.

Otro de los grandes retos estudiados en el ensayo es el del pluralismo cultural, al cual se le dedica el cuarto capítulo (pp. 184-236) además de unas páginas introductorias en la primera parte del libro (pp. 75-80). Lo resumido bajo el rotulo de "choque cultural" es siempre utilizado como excusa o justificación de políticas anti-migratorias. Se aduce una supuesta identidad homogénea —estatal — que quedaría puesta en peligro con la entrada de otras influencias y otros actores culturales. Así, se genera un discurso en el cual la clásica insistencia en las diferencias físicas o biológicas queda sustituida por un discurso culturalista; "la cultura, como «categoría articuladora», ha ocupado el lugar dejado por el esencialismo biológico tan característico del racismo tradicional" (pp. 220-221), dando lugar a lo que Velasco identifica como "neorracismo".

Las migraciones suponen —mediante la conformación de identidades colectivas - el cuestionamiento de las narraciones basadas en un mito identitario. Sin negar las dificultades existentes, frente a este tipo de planteamientos Velasco 
propone la comprensión de los procesos de adaptación cultural como bidireccionales, es decir, como "una labor de ajuste mutuo que ha de desembocar en la construcción de un nuevo marco normativo y narrativo construido en común" (p. 211). Mediante la adopción de un enfoque posmulticultural, Velasco cuestiona los discursos que esencializan las diferencias culturales y que "utilizan de manera interesada la diferencia cultural para justificar la desigualdad en el acceso y el ejercicio del poder y la riqueza" (p. 202).

Para ir concluyendo, es preciso hacer mención de dos de las propuestas constructivas esbozadas por Velasco: la creación de instituciones de gobernanza global y una política de fronteras abiertas. Ambas se desprenden de un entendimiento previo de las fronteras y de la migración desde la óptica de la justicia y el poder. Así, Velasco subraya la importancia de entender este asunto como un problema de justicia global (cap. 5). Aquí el autor construye una crítica a la teoría de la justicia de Rawls, el cual sitúa los límites de la justicia como límites en el estado, y se posiciona frente a ella (pp. 241-264).

Una vez que la movilidad humana es entendida como derecho ésta no puede desligarse de ningún modo de la justicia y, como tal, su ejercicio debería estar garantizado de manera universal. Sería aquí donde la creación de instituciones de gobernanza global tendría lugar, como herramientas a través de las cuales regular la movilidad humana superando así los problemas inherentes a la lógica y estructura estatal. Al mismo tiempo, ello pasa también por un nuevo entendimiento de la ciudadanía en clave cosmopolita o universal. De este modo - aquí Velasco sigue de cerca a Hannah Arendt- se trataría de sobreponer la ley sobre la nación (p. 60), invirtiendo el orden actual de las cosas, para garantizar así los derechos fundamentales de un individuo simplemente por el hecho de ser "persona" y no en base a la posesión de una determinada ciudadanía vinculada a la nacionalidad de un país para que, así, "lo que es el privilegio de unos se convierta en derechos de todos" (p. 143).

Así, Velasco subraya la necesidad de establecer una política de fronteras abiertas (cap. 6) que vaya más allá de la mera gestión y planificación de los flujos migratorios, como es el caso de las ineficaces políticas migratorias vigentes. Actualmente, los Estados actuales estarían decantándose por lo que Velasco conceptualiza como "la opción liberal incoherente" en la cual se reconoce el derecho a emigrar pero se niega, al mismo tiempo, el derecho a inmigrar (p. 298) dándose así una "configuración asimétrica del derecho a migrar" (p. 299). De este modo, los gobiernos estatales estarían defendiendo una posición incoherente e inconsecuente con los supuestos valores en los que sus democracias liberales se sostienen. 
Resulta necesario ampliar la noción de responsabilidad ante las desigualdades globales (p. 313). El enfoque estadocéntrico resulta inadecuado e ineficaz para abordar tales problemas y se precisa por tanto de la adopción de una perspectiva que trate el problema como relativo a una justicia distributiva global. Un enfoque que tenga en cuenta el origen estructural de las desigualdades imperantes y que, por lo tanto, abogue por una reordenación estructural del sistema económico (p. 313) y que pase por rediseñar el orden jurídico-económico internacional (p. 314). Respecto a estas desigualdades Velasco señala la obligación compensatoria que los países beneficiarios de privilegios tendrían respecto a los que carecen de ellos. Así, se trata de "arbitrar una política de fronteras abiertas que, además de constituir un modo de poner en práctica el derecho humano a la libre circulación, desempeñaría esa función compensatoria" (p. 316). Por supuesto, Velasco reconoce que otras muchas soluciones que eliminen las condiciones estructurales que mantienen las desigualdades globales pueden ser pensadas (p. 310) pero, ante la ausencia de instituciones globales que garanticen la libre movilidad, los estados no deberían rehusar su responsabilidad y obligaciones respecto a las personas que se desplazan.

En resumen, El azar de las fronteras proporciona herramientas fundamentales con las cuales conceptualizar la problemática en torno a las fronteras y los procesos migratorios internacionales contemporáneos. De plena actualidad, este libro es una lectura obligada para quien busque hacer frente de una manera ordenada y completa al importante debate al que asistimos en nuestros días.

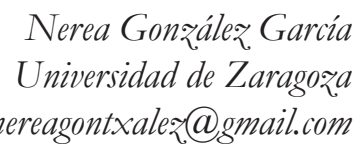

